\title{
The Preterm Rat: A Model for Studies of Acute and Chronic Neonatal Lung Disease
}

\author{
A. K. TANSWELL, L. WONG, F. POSSMAYER, AND B. A. FREEMAN \\ Departments of Paediatrics [A.K.T.,L.W.], Anatomy [A.K.T.], Biochemistry and Obstetrics and Gynaecology \\ [F.P.], University of Western Ontario, and the Lawson Research Institute, St. Joseph's Health Centre, London, \\ Canada, and the Departments of Anesthesiology and Biochemistry [B.A.F.], University of Alabama at
}

Birmingham, Birmingham, Alabama 35294

\begin{abstract}
A preterm rat model has been developed for studies of acute and chronic neonatal lung disease. Premature delivery $24 \mathrm{~h}$ before the normal time of delivery is associated with immature pulmonary phospholipid and antioxidant enzyme profiles. The premature lung is more fragile and ruptures at a lower lung vol $(172 \pm 8 \mu \mathrm{L})$ than the full-term fetal lung $(259 \pm 14 \mu \mathrm{L})$. Only $7 \%$ of premature lungs will float in liquid, after inflation to $85 \%$ of the rupture vol, compared with $87 \%$ of term fetal lungs. This lung immaturity was reflected in a survival rate of only $6 \%$ by $36 \mathrm{~h}$ after delivery if the preterm pups were placed in air, which increased to $47 \%$ when they were placed in $>95 \%$ oxygen. Though $>95 \%$ oxygen enhanced survival of preterm pups during the 1st wk of life, these survivors had a $\mathbf{5 0 \%}$ mortality during the 2nd wk of exposure to $>\mathbf{9 5} \%$ oxygen. The preterm pup will tolerate intraperitoneal injection of antioxidant enzymes entrapped in liposomes and has a better retention of these liposomes in the lung compared with the term pup. We conclude that the preterm rat is a suitable model for studies of acute and chronic neonatal lung disease. (Pediatr Res 25: 525-529, 1989)
\end{abstract}

\section{Abbreviations}

BPD, bronchopulmonary dysplasia DPPC, dipalmitoylphosphatidylcholine

PC, phosphatidylcholine

PG, phosphatidylglycerol

SOD, superoxide dismutase

BPD is most commonly observed in newborn infants that have required high oxygen concentrations and respirator support as a result of pulmonary insufficiency of prematurity (1). This pulmonary insufficiency may be attributed to a number of factors including limited saccular and capillary bed development, immaturity of the surfactant system and, frequently, patency of the ductus arteriosus. The subsequent development of BPD has been related to gestational age at the time of birth (2), duration of exposure to $>40 \%$ oxygen (2), and to barotrauma (3). It is probable that the disease results from a complex interaction of multiple factors and that no single factor is acting alone to produce BPD. We have been particularly interested in the role played by elevated inspired oxygen concentrations and, with

Received September 26, 1988; accepted December 8, 1988.

Correspondence Dr. Keith Tanswell, Lawson Research Institure, St. Joseph's Health Centre, 268 Grosvenor Street, London, Ontario N6A 4V2, Canada.

Supported by Grants MT7867 and MT4957 from the Medical Research Council of Canada and HL40458 from the National Institutes of Health. others, have described a relationship between gestational age and the sp act of pulmonary antioxidant enzymes (4-6). Subsequently, we have demonstrated that full-term newborn rat pups breathing $>95 \%$ oxygen have an $\mathrm{LT}_{50}$ (time to a $50 \%$ mortality) of $13.5 \mathrm{~d}$, and are protected against the lethal effects of $100 \%$ oxygen when given daily intraperitoneal injections of antioxidant enzymes trapped within liposomes (7).

While such studies do demonstrate the protective effect of prophylactic antioxidant enzymes, these promising results in mature neonatal animals (7) or adult animals (8) are not completely satisfactory. Such experimental models do not mimic the usual situation in the preterm human neonate, in which there is a combined biochemical and anatomic immaturity of the lung at the onset of oxygen exposure. A well-characterized baboon model, for the development of BPD in the immature lung, has been described (9). Ethical and economic considerations make this large animal model unsuitable for screening therapeutic agents and delivery systems for effect on lung injury. As far as we are aware, the only reported small animal model of prematurity capable of long term survival is the rabbit (10). The rabbit has been used for oxygen exposure studies (11), and does have an advantage with respect to individual pup size. The disadvantages of the rabbit are the small litter size, expense, and the large exposure facilities required to house each litter with a dam for chronic exposures. In this report we describe both the development of a premature rat model for use in oxygen exposure studies and the sensitivity of this model to $100 \%$ oxygen.

\section{METHODS}

Materials. Timed pregnant Sprague-Dawley rats (250-300 g) were purchased from Charles Rivers Inc. (St. Constant, Quebec) as pairs mated $24 \mathrm{~h}$ apart with brown hooded males. All solvents were chromatography grade and were obtained from Sigma Chemical Co. (St. Louis, MO). Small vein Teflon catheters $(0.011$ $\mathrm{cm}$ outer diameter, $0.39 \mathrm{~cm}$ length) were obtained from Becton Dickinson (Rutherford, NJ). Isotopes were obtained from New England Nuclear (Boston, MA), and counted in $\beta$ or $\tau$ counters (Tracor Analytic, Elk Grove Village, IL). Bovine CuZn SOD was a generous gift from Grünenthal Gmbh (Aachen, Germany). Stearylamine and cholesterol were from Sigma, catalase from Cooper Biomedical (Malvern, PA) and DPPC was from Avanti Polar Lipids (Birmingham, AL).

Preliminary Experiments. Anesthetic agent. A number of litters were delivered abdominally under the influence of various anesthetic agents, in an attempt to define the agent with the least depressant effect on the fetuses. These agents included intraperitoneal pentobarbitone and tribromethanol, and inhalational ether, chloroform, and halothane. Our experience was similar to that reported by Lorenzo with premature rabbits (10), in that none of these agents provided adequate anesthesia in the mother 
without significant fetal depression. Like Lorenzo (10), we had to resort to killing the mother, in a saturated atmosphere of chloroform, and then perform an immediate hysterotomy to deliver the pups.

Timing of delivery. Abdominal deliveries were performed at various intervals up to $36 \mathrm{~h}$ before the expected time of delivery (22 d). Pups delivered $>24$ h prematurely failed to survive the immediate postdelivery period, not because of respiratory failure, but because the normal habit of the mother to step on the pups caused them to be crushed. This was tolerated by pups delivered $\leq 24 \mathrm{~h}$ before the expected time of delivery. This timing was also convenient in that abdominal delivery could be started as soon as the matched term surrogate mother had delivered her own pups vaginally. The use of pairs of animals mated $24 \mathrm{~h}$ apart allowed premature litters immediate access to a lactating surrogate mother freshly delivered at term.

Environmental temperature. One previous report of short-term studies with prematurely delivered rats used an environmental temperature of $37^{\circ} \mathrm{C}(12)$. We examined a range of environmental temperatures and found that $37^{\circ} \mathrm{C}$ was unsatisfactory for these longer term studies, in which the surrogate mother was to be housed with the pups. The mother was obviously overheated and distressed and would neither suckle the young nor maintain a nest. At room temperatures, the preterm pups were inactive and did not group to retain body heat. By trial and error we determined that an environmental temperature of $25-26^{\circ} \mathrm{C}$ resulted in appropriate behavior by both mother and pups.

Acceptance by surrogate mother. In our exposure studies with term pups (7), only one of 31 litters were not accepted by a surrogate mother. In these studies, with abdominally delivered preterm animals, the first five litters delivered were immediately cannibalized by the surrogate mother. This problem was resolved by careful washing of the pups in $25-26^{\circ} \mathrm{C}$ tap water to remove all traces of blood from their skin. The pups were then uniformly accepted by the surrogate mother.

Cord bleeding. After the pups had been washed, the umbilical cords were crushed gently with rubber-sheathed forceps and cut to remove the placenta. In early experiments, a number of pups were lost through cord bleeding. This was overcome by delaying the removal of the placenta until after the pups had been washed, after which cord bleeding was rare.

Exposure Protocol. As soon as a potential surrogate mother (d 22) had delivered, she was placed into a $>95 \%$ oxygen exposure chamber with her pups. A premature litter (d 21) was then delivered by hysterotomy, washed free of blood and placed into Petri dishes under an infant warmer. The bottom of the dishes were percussed with a pencil until regular respirations were established. If $<12$ pups had regular respirations by $30 \mathrm{~min}$ after delivery, a second litter (d 21) was delivered by hysterotomy to ensure that 12-16 pups were presented to the surrogate mother. The mothers from which the preterm pups were obtained were killed with a lethal exposure to chloroform. The surrogate mother's pups (d 22) were then removed and replaced by the preterm (d 21) pups. A second freshly delivered mother and litter of term pups (d 22) were placed in a parallel air exposure chamber. This procedure was repeated to obtain a preterm litter for air exposure. All exposures were thus conducted in two pairs, with the mothers exchanged after $12 \mathrm{~h}$, and then each $24 \mathrm{~h}$, to avoid the lethal effects of inhaled oxygen on the mother. The exposure system has been described in detail previously (7). It basically consisted of four $30-\times 30-\times 15-\mathrm{cm}$ plastic chambers with inlet and outlet ports for humidified $\mathrm{O}_{2}$ or air. The relative humidity within the chambers was $85 \pm 2 \%$, and the flow rates were maintained to keep chamber $\mathrm{CO}_{2}$ concentrations $<0.05 \%$, with an $\mathrm{O}_{2}$ concentration $>95 \%$ in the $\mathrm{O}_{2}$ chamber. Paired chambers were maintained in human neonatal incubators to maintain chamber temperature at $25 \pm 1{ }^{\circ} \mathrm{C}$. The exposure room had a $12: 12 \mathrm{~h}$ on:off light cycle. Chambers were bored to allow entry of a water bottle spout to provide water ad libitum. The hinged face plate of each chamber was opened for $\approx 5 \mathrm{~min}$ each $\mathrm{d}$ to allow exchange of mothers, change of bedding, and replacement of food pellets. Gas flow to the oxygen chambers was increased during the time the chamber face plate was open.

Mortality curves. Only pups that had active respiration established $30 \mathrm{~min}$ after delivery were included in the statistical analysis. Deaths prior to $30 \mathrm{~min}$ of age were considered to be delivery related. Surviving pups were counted at $12 \mathrm{~h}$ from birth, and then daily until the completion of the 13.5-d exposure period. As litter size varied slightly, the survival rates were plotted as percentage of survival from the original number actively breathing at $30 \mathrm{~min}$ from delivery.

Lung Phospholipid/Antioxidant Enzyme Profiles. Lungs were removed from six preterm and four term litters for estimation of superoxide dismutase (EC 1.15.1.1.), catalase (EC 1.11.1.6), and glutathione peroxidase (EC 1.11.1.9) activity, after correction for blood contamination, as described previously (5).

Lungs were removed from five preterm and six term litters for phospholipid analysis. The lungs were pooled for each litter after each lung had been cut into several slices. The lung fragments were washed several times to remove erythrocytes, then the lung slices were blotted dry, and the pooled lung tissue from each litter was weighed. The lung tissue was then homogenized and lipids extracted as described by Folch et al. (13). Phospholipids were chromatographed in the solvent system described by Touchstone et al. (14), as previously described (15).

For these studies, and the studies of inflation vol and the lungs capacity to float, the preterm pups were delivered as described above. The term pups were also delivered by hysterotomy, after vaginal delivery of the first pup and rapid killing of the mother. The first pup delivered vaginally was not used for the analyses.

Maximum Tolerated Inflation Vol. Attempts to measure static lung compliance by a technique that can be used in rats as young as $3 \mathrm{~d}$ of age (16) were unsuccessful when applied to the fluidfilled premature newborn lung. During these attempts, it was noted that the premature lung was more friable that the term fetal lung, with rupture occurring at lower inflation vol. The maximum tolerated inflation vol was estimated in 19 premature pups from four litters delivered $24 \mathrm{~h}$ early and in 15 term pups from three litters. The pups were killed with a lethal dose of pentobarbital $(150 \mathrm{mg} / \mathrm{kg}$ as $30 \mu \mathrm{L}$ of a $25-\mathrm{mg} / \mathrm{mL}$ solution) by intraperitoneal injection in utero, while the mother was under ketamine/xylazine anaesthesia. After delivery, the temperomandibular joints were transected bilaterally. The lower jaw could then be reflected to bring the epiglottis and vocal cords into view. Intubation was then simply performed with a 26-gauge intravenous catheter (without stylet), which was sutured in place with two purse string sutures around the area of the larynx. The diaphragm was then opened through the abdomen and the anterior chest wall removed. The lungs were inflated under water with 10- $\mu$ l aliquots of air and the rupture vol was recorded. Specimens were discarded if air leaks were observed from the suture line or at vol below $100 \mu \mathrm{l}$.

Capacity of Lungs to Float. Once the maximum tolerated inflation vol had been determined, lungs from 15 preterm and 15 term pups, from three litters each, were inflated to $85 \%$ of the determined maximum vol for each group. Only those specimens that did not rupture during the inflation period were retained. These lungs were allowed to deflate passively and were placed in saline to determine if they would float.

Liposome Uptake. As this preterm model is to be used in studies of various antioxidant agents, the uptake of intraperitoneally injected liposomes containing ${ }^{125} \mathrm{I}$-superoxide dismutase was examined. Liposome preparation has been described in detail elsewhere (7). Our previous studies with term pups had demonstrated that peak uptake in most organs occurred $4 \mathrm{~h}$ after injection, and this single time point was used in these studies with the preterm pups. The $25-\mu \mathrm{L}$ injection vol of liposome suspension contained $433 \mathrm{U}$ SOD, with a sp act of $3.74 \times 10^{5}$ $\mathrm{cpm}^{125} \mathrm{I} / 1000 \mathrm{U}$ SOD, and $7788 \mathrm{U}$ catalase. Organs were removed from 11 term pups and 14 preterm pups from three 
separate litters, thoroughly washed to remove surface contamination with liposomes, and blotted dry. After weighing, they were counted in a $\tau$-counter for estimation of ${ }^{125} I$ content. This value was used to calculate organ uptake of liposome entrapped SOD and catalase.

Statistical Analysis. Comparisons were conducted by analysis of variance followed by Dunnett's test (17), except for the comparison of preterm and term lungs that would float after inflation, which was conducted by a $\chi^{2}$ analysis followed by a Fisher exact test (18). Differences were considered significant if $p<0.05$. All values are shown as mean \pm SEM.

\section{RESULTS}

The immaturity of the lungs of rat pups delivered $24 \mathrm{~h}$ before term was confirmed biochemically (Table 1), by their reduced antioxidant enzyme activities and immature phospholipid profiles. The mean activities of SOD, catalase, and glutathione peroxidase increased $44 \%, 43 \%$, and $198 \%$, respectively, during the last $24 \mathrm{~h}$ of gestation. The total PC content of the lung increased $\approx 50 \%(f=38.214, p<0.001)$, as did the DPPC content $(f=67.276, p<0.001)$, while the $\mathrm{PG}$ content increased $\approx 100 \%(f=65.792, p<0.001)$ over the last 24 h of gestation. This immaturity of the lung surfactant system was supported by the observation $\left(\chi^{2}=16.205, p<0.001\right)$ that only $7 \%(1$ of 15$)$ of immature lungs could float after lung inflation, whereas $87 \%$ (13 of 15) term lungs floated. Immaturity of parenchymal lung development was suggested by a rupture vol of $172 \pm 8 \mu \mathrm{L}$ for the premature lung, compared with $259 \pm 14 \mu \mathrm{L}$ for the term lung $(f=36.493, p<0.001)$.

The basic parameters of the exposure groups are shown in Table 2. There were no differences in litter size for the six litters used for air exposure, or the 12 litters used for oxygen exposure. Of these 18 litters there were 13 litters used intact for exposure. The five additional litters were partially used to contribute pups to other litters, where survival at $1 \mathrm{~h}$ had fallen below the defined limits. Survival at $1 \mathrm{~h}$ was, on average, better than $80 \%$ of the delivered pups. The majority of these losses were due to umbilical cord bleeding in pups from the initial litters studied.

The survival curves for the exposure groups are shown in Figure 1. Survival in air fell from $70 \%$ at $12 \mathrm{~h}$ of age to $6 \%$ at $36 \mathrm{~h}$ of age. In oxygen, however, the survival was $80 \%$ at $12 \mathrm{~h}$ and $47 \%$ by $36 \mathrm{~h}$ of exposure, and remained relatively stable until $9 \mathrm{~d}$ of age. Survival was essentially halved over the remaining exposure period from $41 \%$ on $\mathrm{d} 8$ to $23 \%$ on $\mathrm{d} 14$.

As shown in Table 3, organ uptake of liposome entrapped enzymes injected intraperitoneally was greater in preterm pups than in term pups. For the lung, this resulted in a more than 2 fold increase in the enzyme delivered $(f=4.751, p=0.04)$.

\section{DISCUSSION}

Delivery of rat pups $24 \mathrm{~h}$ before the expected time of delivery is feasible. As with the preterm rabbit model (10), depression of pups due to transplacental passage of anesthetic agents was a major problem. This necessitated killing the mothers followed by rapid delivery, both with the rabbit study (10) and in this study. As blood gas sampling is not easily conducted on fetal rats, we cannot be certain that some pups were not asphyxiated at the time of delivery-even though all were delivered within

Table 2. Basic parameters of preterm pup study groups

\begin{tabular}{lcc}
\hline & Air & $\mathrm{O}_{2}$ \\
\hline No. pups/litter at delivery & $12 \pm 1$ & $11 \pm 1$ \\
No. hysterotomies performed & 6 & 12 \\
\% survival at $1 \mathrm{~h}$ & $76 \pm 7$ & $86 \pm 7$ \\
No. litters exposed & 5 & 8 \\
No. pups $(1 \mathrm{~h})$ in exposed litters & $11 \pm 2^{*}$ & $14 \pm 2^{*}$ \\
No. pups/litter at $2.5 \mathrm{~d}$ & $1 \pm 1$ & $6 \pm 2$ \\
\hline
\end{tabular}

* Litter sizes were increased when necessary by pooling pups from two hysterotomies.

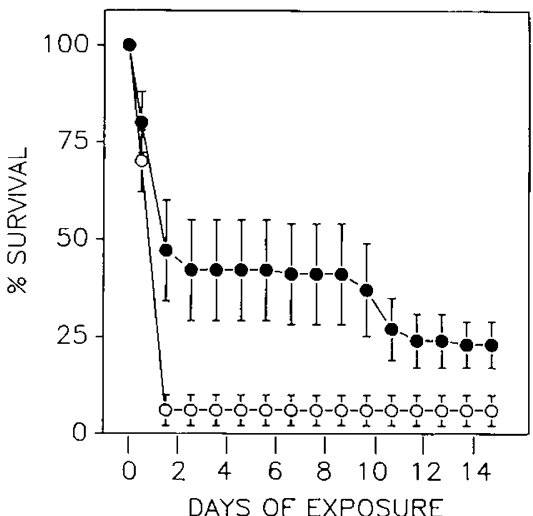

Fig. 1. Survival of preterm pups delivered into air $(O)$ or $>95 \%$ $\mathrm{O}_{2}$ over a 14.5-d exposure period. All values are shown as mean \pm SEM for five litters exposed to air and eight litters exposed to $>95 \% \mathrm{O}_{2}$, and represent percentage of survival of those pups that had a regular respiratory pattern present $\mathrm{l} \mathrm{h}$ after delivery by hysterotomy.

Table 1. Indices of lung maturity in the 24-h preterm fetal rat

\begin{tabular}{|c|c|c|c|c|}
\hline & $(n)$ & preterm & $(n)$ & term \\
\hline Lung wet wt (mg/pup) & (5) & $105 \pm 6$ & (6) & $117 \pm 2$ \\
\hline $\begin{array}{l}\text { Blood content ( } \mu \mathrm{L} / \text { lung) } \\
\text { Lung antioxidant enzyme activity }\end{array}$ & (6) & $0.77 \pm 0.08$ & (4) & $0.69 \pm 0.38$ \\
\hline Superoxide dismutase (U/g wet $w t)$ & \multicolumn{3}{|c|}{ Lung antioxidant enzyme activity } & \\
\hline Catalase $(\mathrm{U} / \mathrm{g}$ wet wt) & (6) & $979 \pm 87$ & (4) & $1402 \pm 572$ \\
\hline $\begin{array}{l}\text { Glutathione peroxidase (mU/g wet } \\
\text { wt) }\end{array}$ & (6) & $62 \pm 28$ & (4) & $185 \pm 120$ \\
\hline \multicolumn{5}{|l|}{ Total lung phospholipid ( $\mu \mathrm{g} / \mathrm{mg}$ wet $\mathrm{wt}$ ) } \\
\hline PC & (5) & $6.10 \pm 0.25^{*}$ & (6) & $8.96 \pm 0.27$ \\
\hline DPPC & (5) & $1.96 \pm 0.10^{*}$ & (6) & $3.12 \pm 0.10$ \\
\hline$\%$ saturation $\mathrm{PC}$ & (5) & $32 \pm 1$ & (6) & $35 \pm 1$ \\
\hline PG & $(5)$ & $0.49 \pm 0.02 *$ & (6) & $0.98 \pm 0.05$ \\
\hline Inflation vol at rupture $(\mu \mathrm{L})$ & (19) & $172 \pm 8^{*}$ & (15) & $259 \pm 14$ \\
\hline Ability to float (\%) & $(15)$ & $7^{*}$ & $(15)$ & 87 \\
\hline
\end{tabular}

\footnotetext{
$* P<0.001$
} 
Table 3. Antioxidant enzyme uptake into organs $4 \mathrm{~h}$ after intraperitoneal liposome injection $(\mathrm{U} / \mathrm{g} \text { wet } w t)^{*}$

\begin{tabular}{lccccc}
\hline & \multicolumn{2}{c}{ Term } & & \multicolumn{2}{c}{ Preterm } \\
\cline { 2 - 3 } \cline { 5 - 6 } & SOD & Catalase & & SOD & Catalase \\
\hline Spleen & $287 \pm 100$ & $5079 \pm 1777$ & & $338 \pm 88$ & $5989 \pm 1558$ \\
Liver & $57 \pm 11$ & $1003 \pm 198$ & & $80 \pm 13$ & $1423 \pm 236$ \\
Kidney & $27 \pm 3$ & $483 \pm 46$ & & $63 \pm 9$ & $1102 \pm 161$ \\
Lung & $7 \pm 1$ & $124 \pm 4$ & & $16 \pm 4$ & $274 \pm 69$ \\
Brain & $3 \pm 1$ & $48 \pm 4$ & & $4 \pm 1$ & $69 \pm 8$ \\
\hline
\end{tabular}

* All values are mean \pm SEM for 11-14 pups from three litters. Enzyme activity has been calculated from the organ content of ${ }^{125}$ I $4 \mathrm{~h}$ after the intraperitoneal injection of $25 \mu \mathrm{L}$ of a liposome suspension with a sp act of $3.7 \times 10^{5} \mathrm{cpm}{ }^{125} \mathrm{I} / 1000 \mathrm{U}$ SOD.

3-5 min of maternal death. For this reason, and because of some problems with hemostasis in the first litters studied, we included only pups that had active regular respirations at $1 \mathrm{~h}$ of age in the analysis of the exposure groups. The observed need for an elevated environmental temperature for preterm animals would be predicted from human observations. The preterm pups' malaise at room temperature, with more normal behavior at 25 $26^{\circ} \mathrm{C}$, presumably reflects reduced liver glycogenolysis and hypoglycemia, which occurs with hypothermia at this gestational age (19).

We have previously documented a gestation-dependent increase of fetal lung antioxidant enzymes (5). The differences observed between activities for preterm and term fetuses in this study were of a magnitude that we would expect from our previous observations (5), even though statistical significance was not achieved. Blood contamination was reduced to approximately $10 \%$ of that observed previously (5) by cutting the lung tissue into strips before washing. The whole lung phospholipid profiles confirm previous reports that rats delivered $24 \mathrm{~h}$ prematurely have significantly reduced lung phospholipid concentrations $(20,21)$. Our results showed somewhat less than the 2 fold increase of saturated PC and 5-fold increase of PG over the last $24 \mathrm{~h}$ of gestation reported by Bourbon et al. (21) but still suggested surfactant system immaturity $24 \mathrm{~h}$ before term. This immaturity of surfactant development was reflected in the inability of the preterm lungs to retain sufficient air to float following inflation. The lesser inflation vol at which the preterm lung was observed to rupture may have reflected immaturity of both lung parenchyma and the surfactant system. These combined observations confirm that the fetal rat lung $24 \mathrm{~h}$ before the expected time of delivery is immature, and it offers a better small animal model for studies of oxygen toxicity than the term rat pup, in that it is both surfactant and antioxidant enzyme insufficient. The 6\% 24-h survival in room air of the preterm pups is compatible with the $10 \%$ 6-h survival in $40 \% \mathrm{O}_{2}$ at this gestational age reported by Frank et al. (12). It is interesting that mortality is greatest in the second $12 \mathrm{~h}$ of life for preterm pups delivered into air. It is possible that this reflects the initial consumption of surfactant stores, with a subsequent inability to synthesize new surfactant (22). An increased early survival in $>95 \% \mathrm{O}_{2}$, as observed in our studies, would have been predicted, on the basis of pulmonary insufficiency leading to hypoxemia in the airbreathing preterm pups. Measurements of plasma lactate/pyruvate ratios in preterm pups of this gestational age suggest the presence of hypoxemia, which is correctable by oxygen administration (23).

The pups in $>95 \% \quad \mathrm{O}_{2}$ that survived the initial period of perinatal adaptation had a $50 \%$ mortality during the $2 \mathrm{wk}$ of oxygen exposure. This mortality rate is essentially the same as that observed in full-term pups under the same conditions (7). The feasibility of prophylactic therapy using liposome-entrapped antioxidant enzymes was examined in this model. The delivery of enzyme to the lungs after intraperitoneal injection was greater in the preterm animal, suggesting that the peritoneum may be even more permeable in the preterm than in the full-term pup. The disadvantage of parenteral delivery of liposomes is that only $3-4 \%$ of the liposome dose is taken up by the lung (Table 3), while there is massive deposition which occurs in the reticuloendothelial system (7). This will probably limit their use in human infants, unless techniques are developed that can target liposomes to a specific organ.

The preterm rat model is a viable alternative to the preterm rabbit, as a model for studies of chronic lung injury. Specifically it will allow studies of combined surfactant and antioxidant enzyme therapy in the preterm lung, which has deficiencies of both enzyme systems. One approach would be delivery down the airway, as currently conducted with prophylactic surfactant therapy (24). An advantage of this approach is that liposomes are applied directly to the pulmonary epithelium, which responds to oxygen injury by an increase in permeability (25). Transient intubation is not practicable in the preterm rat model due to size limitations, but it should be possible to use the approach taken by Metcalfe et al. (26) in the preterm rabbit of delivery to the upper airway before the first breath. The inclusion of surfactant with the liposomes may allow liposomes to be cometabolized with the surfactant (27), and allow a more even distribution of the enzymes over the epithelial surfaces of the lung.

Acknowledgements. The authors thank C. Nenadovich, M. A. Ormseth, M. Reynolds, and P. Tanswell for their expert technical assistance.

\section{REFERENCES}

1. O'Brodovich HM, Mellins RB 1985 Bronchopulmonary dysplasia: unresolved neonatal acute lung injury. Am Rev Respir Dis 132:694-709

2. Edwards DK, Dyer WM, Northway WH 1977 Twelve years' experience with bronchopulmonary dysplasia. Pediatrics 59:839-846

3. Taghizadeh A, Reynolds EOR 1976 Pathogenesis of bronchopulmonary dysplasia following hyaline membrane disease. Am J Pathol 82:241-246

4. Frank L, Groseclose EE 1984 Preparation for birth into an $\mathrm{O}_{2}$-rich environment: the antioxidant enzymes in the developing rabbit lung. Pediatr Res $18: 240-244$

5. Tanswell AK, Freeman BA 1984 Pulmonary antioxidant enzyme maturation in the fetal and neonatal rat: I. Developmental profiles. Pediatr Res 18:584587

6. Gercin E, Tyden O, Eriksson UJ 1985 The development of antioxidant enzymatic defense in the perinatal rat lung: activities of superoxide dismutase, glutathione peroxidase and catalase. Pediatr Res 19:687-691

7. Tanswell AK, Freeman BA 1987 Liposome-entrapped antioxidant enzymes prevent lethal $\mathrm{O}_{2}$ toxicity in the newborn rat. $\mathrm{J}$ Appl Physiol 63:347-352

8. Turrens JF, Crapo JD, Freeman BA 1984 Protection against oxygen toxicity by intravenous injection of liposome entrapped catalase and superoxide dismutase. J Clin Invest 73:87-95

9. Coalson JJ, Kuehl TJ, Escobedo MB, Hilliard JL, Smith F, Meredith K, Null DM, Walsh W, Johnson D, Robotham JL 1982 A baboon model of bronchopulmonary dysplasia: II. Pathological features. Exp. Mol Pathol 37:335350

10. Lorenzo AV 1985 The preterm rabbit: a model for the study of acute and chronic effects of premature birth. Pediatr Res 19:201-205

11. Frank L, Bucher JB, Roberts RJ 1978 Oxygen toxicity in neonatal and adult animals of various species. J Appl Physiol 45:699-704

12. Frank L, Lewis PL, Sosenko IRS 1985 Dexamethasone stimulation of fetal rat lung antioxidant enzyme activity in parallel with surfactant stimulation. Pediatrics 75:569-574

13. Folch J, Less M, Sloane-Stanley GH 1957 A simple method for the isolation and purification of total lipids from animal tissues. $\mathbf{J}$ Biol Chem 226:497509

14. Touchstone JC, Chen JC, Beaver KM 1980 Improved separation of phospholipids in thin layer chromatography. Lipids 15:61-62

15. Yu S-H, Smith N, Harding PRG, Possmayer F 1983 Bovine pulmonary surfactant: chemical composition and physical properties. Lipids 18:522529

16. Newman LM, Johnson EM, Roth JM 1984 Lung volume and compliance in neonatal rats. Lab Anim Sci 34:371-375

17. Steel RGD, Torrie JH 1970 Principles and Procedures of Statistics. McGraw Hill, New York, p 188

18. Snedecor GW, Cochran WG 1980 Statistical Methods. Iowa State University Press, Ames, IA, p 127

19. Cuezva JM, Benito M, Moreno FJ, Medina JM 1980 Prematurity in the rat. II. Effect of hypothermia. Biol Neonate 37:218-223 
20. Juanes MC, Arizmendi C, Medina JM 1986 Attenuation of postnatal hypoxia in the premature newborn rat by maternal treatment with dexamethasone: its relationship with lung phospholipid content. Biol Neonate 50:337-344

21. Bourbon JR, Farrell PM, Doucet E, Brown DJ, Valenza C 1987 Biochemical maturation of the fetal rat lung: a comprehensive study including surfactant determination. Biol Neonate 52:48-60

22. Jobe A, Gluck L 1979 The labeling of lung phosphatidylcholine in premature rabbits. Pediatr Res 13:635-640

23. Cuezva JM, Medina JM 1981 Prematurity in the rat: III. Effects of oxygen supply. Biol Neonate 39:70-77
24. Smyth JA, Metcalfe IL, Duffty P, Possmayer F, Bryan MH, Enhorning G 1983 Hyaline membrane disease treated with bovine surfactant. Pediatrics $71: 913$ 917

25. Matalon S, Egan EA 1984 Interstitial fluid volumes and albumin spaces in pulmonary oxygen toxicity. J Appl Physiol 57:1767-1772

26. Metcalfe IL, Burgoyne R, Enhorning G 1982 Surfactant supplementation in the preterm rabbit: effects of applied volume on compliance and survival. the preterm rabbit: effects
Pediatr Res 16:834-839

27. Jobe A, Ikegami M 1987 Surfactant and the treatment of respiratory distress syndrome. Am Rev Respir Dis 136:1256-1275 